\title{
NIKOLAI LESKOV E O ANIMISMO: FALAR COM PEDRAS NO CONTO ALEXANDRITA
}

\author{
Nikolai Leskov and animism: speaking with stones in the short story The \\ Alexandrite
}

\author{
Marcos Lampert Varnieri \\ https://orcid.org/0000-0001-9014-6617 \\ Universidade Federal do Rio Grande do Sul, Porto Alegre, RS, \\ Brasil.91501-970 - ppglet@ufrgs.br
}

Resumo: O conto Alexandrita (um fato natural à luz do misticismo), do autor russo Nikolai Leskov (1831-1895), apresenta-se particularmente adequado a uma leitura anímica de seus aspectos insólitos. A personalização das pedras alexandrita e piropo, minerais preciosos que representam as nações russa e tcheca respectivamente, dá à narrativa a hesitação necessária para uma caracterização fantástica, segundo a teoria de Tzvetan Todorov reforçada por David Roas. As duas gemas são tratadas pelo personagem do ourives como dotadas de vida e de alma, características centrais do animismo. Além da concepção anímica, há no conto um contraste entre os saberes civilizados e os chamados tradicionais, pois ao narrador, representante da característica urbana, opõe-se o velho ourives cabalista e místico, guardião da tradição popular de sua terra. Walter Benjamin (1936) retoma a obra de Leskov em sua conhecida teorização acerca da arte de narrar. A qualidade narrativa por ele prezada está contida no modo artesanal como Leskov constrói suas obras. Tal reflexão sobre a arte literária está também em Sigmund Freud, que tece considerações aproximando a psicologia e a antropologia da literatura. O conto Alexandrita é, portanto, o ponto de encontro de conceitos e disciplinas díspares visto ser ele valioso como os objetos e saberes que descreve.

Palavras-chave: Nikolai Leskov; Alexandrita; Animismo; Fantástico literário.

\begin{abstract}
The short story The Alexandrite, by the Russian author Nikolai Leskov (1831 - 1895), is particularly suited to an animistic reading of its unusual aspects. The personalization of the alexandrite and garnet (pyrope) stones, precious minerals representing the Russian and Czech nations respectively, gives the narrative the necessary hesitation for a fantastic characterization, according to Tzvetan Todorov's theory reinforced by David Roas. The two gems are treated by the character of the goldsmith as endowed with life and soul, central features of animism. In addition to the animistic conception, there is in the story a contrast between civilized and traditional wisdoms, for the narrator, representative of the urban characteristic, opposes the old Kabbalist and mystic goldsmith, guardian of the popular tradition of his land. Walter Benjamin (1936) analyses the work of Leskov in his well-known theorizations about the art of narrating. The narrative quality prized by him is contained in the artisanal way Leskov constructs his works. Such a reflection on the literary art is also present in Sigmund Freud, who weaves considerations approaching psychology and anthropology with literature. The short story The Alexandrite is, therefore, the meeting point of disparate concepts and disciplines since it is as valuable as the objects and knowledge it describes. Keywords: Nikolai Leskov; Alexandrite; Animism; Fantastic.
\end{abstract}




\section{Introdução}

O presente artigo examina, a partir dos conceitos de animismo aplicados à literatura, o elemento fantástico presente em um conto russo. Alexandrita (um fato natural à luz do misticismo), de Nikolai Leskov (1831-1895), é o texto escolhido. Um elemento de particular interesse na obra é a relação estabelecida por um dos personagens com as pedras preciosas que encontra.

Nikolai S. Leskov foi um autor russo durante muito tempo negligenciado pela crítica e pelo público. Segundo Elena Vássina (2014), não obteve o mesmo reconhecimento dispensado a seus contemporâneos, como Dostoiévski, em virtude de não aderir às correntes políticas da época, tanto conservadoras quanto revolucionárias, ocasionando crítica e desdenho por seus companheiros de ofício. Além disso, Leskov ousou ao inovar em estilo, incorporando elementos da cultura popular, e antecipou temas posteriormente tratados pela vanguarda russo-soviética dos anos 1910-1920.

Um dos críticos que retoma Leskov e o apresenta à audiência internacional é Walter Benjamin, em seu ensaio O Narrador: considerações sobre a obra de Nikolai Leskov. Benjamin (2014) exalta a capacidade do autor que não reduz o relato à mera informação nem se perde em explicações excessivas. Sobre Leskov, escreve:

A cada manhã recebemos notícias de todo o mundo. E, no entanto, somos pobres em histórias surpreendentes. A razão para tal é que todos os fatos já nos chegam impregnados de explicações. Em outras palavras: quase nada do que acontece é favorável à narrativa, e quase tudo beneficia a informação. Metade da arte narrativa está em, ao comunicar uma história, evitar explicações. Nisso Leskov é magistral [...]. O extraordinário, o miraculoso é narrado com a maior exatidão, mas o contexto psicológico da ação não é imposto ao leitor. Ele é livre para interpretar a história como quiser, e com isso o episódio narrado atinge uma amplitude que falta à informação. (BENJAMIN, 2014, p. 219).

Além dos aspectos narrativos apontados, elementos fantásticos também estão presentes na escrita de Leskov. Visto o próprio subtítulo do conto apresentar o termo misticismo, convém, então, buscar teorias do fantástico para a exegese da narrativa. No texto, são as gemas alexandrita e piropo ou granada de fogo as dotadas de personalidade, portanto, animadas. O animismo - conceito oriundo da antropologia, aqui aplicado aos estudos literários - torna-se fundamental por tratar do processo pelo qual se reconhece vida em seres inanimados. O intuito deste trabalho, portanto, é identificar os elementos animistas no conto em questão. A conceituação animista tem sido empregada nos estudos literários por teóricos contemporâneos como Harry Garuba, membro do Centre for African Studies, e Graham Harvey, teórico dos estudos da religião na Open University. É relevante, ainda, retomar o conceito de animismo presente em obras de Edward Tylor, Sigmund Freud e Émile Durkheim, bem como integrar as reflexões teóricas acerca do literário nos estudos de Walter Benjamin, Tzvetan Todorov e David Roas. 


\section{A pedra viva}

O conto inicia com um narrador de origem russa apresentando a história da pedra preciosa alexandrita. O mineral é descrito primeiramente de modo científico:

O nome "alexandrita" foi dado a essa pedra pelo famoso cientista e mineralogista finlandês Nordenskiöld [...]. A alexandrita (Alexandrit, Chrisoberil Cymophone), mineral valioso, é uma variedade de crisoberilo dos Urais. Tem cor verde-escura, muito parecida com a da esmeralda escura. Sob iluminação artificial, perde esse colorido verde e adquire um tom framboesa. (LESKOV, 2014, p. 148).

Seu nome, entretanto, é atrelado à história do tsar Alexandre II, pois a descoberta da pedra coincidiria com a data de maioridade do soberano. Esse governante alcançou grande prestígio na Rússia, por ter realizado diversas reformas econômicas e políticas, sendo a mais notável a abolição da servidão. Após o assassinato do tsar, diferentes estratos da população russa buscaram adquirir o cristal como lembrança do monarca. Outrossim, também o narrador obtém um anel de alexandrita.

No segundo momento, o objeto de interesse é o piropo ou granada de fogo. $O$ contato do narrador com esse mineral se dá em uma viagem a terras tchecas, empreendida para encontrar uma granada de grande valor a pedido de um amigo. A gema localizada, apesar de bela, estava mal lapidada. Visando a corrigir o trabalho do primeiro joalheiro, o narrador, conversando com outro personagem, ouve a seguinte descrição sobre o ourives que deveria procurar:

É um artista, e não um artesão - disse o tcheco, e contou-me que o velho Wenzel era cabalista e místico, e também, em parte, poeta inspirado e grande supersticioso, porém homem originalíssimo e, por vezes, até muitíssimo interessante. [...] A pedra para o vovô Wenzel, não é um ser sem alma, mas animado. Ele sente nela o reflexo da vida misteriosa dos espíritos das montanhas e, peço-lhe que não ria, estabelece relações misteriosas com eles através da pedra. Às vezes, ele conta sobre revelações recebidas, e as suas palavras fazem muitos pensarem que o pobre velho já não tem tudo em ordem debaixo do crânio. (LESKOV, 2014, p. 153, grifos nossos).

O narrador solicita ao artista que restitua a beleza da joia, ao que o ourives acede. Afirmando conhecer a trajetória individual da gema que tinha diante de si, Wenzel enuncia a primeira ocorrência do fenômeno anímico no texto. Sobre a pedra, o cabalista diz o seguinte:

Sim, é ele [...]. Já nos conhecemos há muito tempo... Eu o vi ainda em sua terra natal, nos campos secos de Merunice. Naquela época, ele se encontrava em sua prisca simplicidade, mas eu o percebi... E quem poderia dizer que o seu destino seria tão terrível? Oh, o senhor pode ver nele como os espíritos das montanhas são cautelosos e perspicazes! (LESKOV, 2014, p. 155).

O relato prossegue com sua aquisição por um ladrão suábio, que realizara a lapidação 
imperfeita e a vendera a um mascate judeu. Wenzel explica que o corte grosseiro decorrera de o suábio ser incapaz de conversar com a pedra:

O suábio não vai conseguir fazer dele o que lhe der na telha. Quiseram fazêlo em rosa; pois o senhor pode ver (eu não vi nada), ele não se entregou. Oh, não! Ele é um piropo, usou de subterfúgios, antes permitiu que os suábios lhe cortassem a cabeça fora, e eles cortaram. (LESKOV, 2014, p. 156).

Enquanto a alexandrita está ligada à memória do falecido tsar, sendo uma pedra russa, o piropo é representante do caráter tcheco. Na prosa tecida pelo ourives, a joia, como o povo tcheco, resistiu à dominação por estrangeiros; mesmo subjugada, não perdeu a identidade e o fogo vital:

Sim, a cabeça é uma coisa importante, meu senhor, mas o espírito... O espírito é ainda mais importante que a cabeça [...]. Mas o tcheco não é desses, ele não se deixa triturar logo no pilão do suábio! Os piropos têm sangue de guerreiro... Ele sabia o que precisava fazer. Fingiu, como o tcheco sob os suábios, entregou a cabeça, mas escondeu o seu fogo no coração... Sim, senhor, foi isso! O senhor não está vendo o fogo? Não? Pois eu vejo: eis aqui o fogo denso e inextinguível da montanha tcheca... Ele está vivo e... por favor, desculpe-o: está rindo do senhor. (LESKOV, 2014, p. 156).

Wenzel, em seguida, conta como o piropo se disfarça nas mãos do mascate judeu, ao assumir o semblante de um limpa-chaminés, ocupação tida entre as de mais baixo prestígio na época. Mais uma vez, em contraste, o cabalista realça as características nobres da gema, afirmando se tratar, mesmo que em exílio, de um rei tcheco, ou um príncipe de Merunice, cidade do antigo reino da Boêmia que ainda hoje carrega em sua heráldica aquele cristal. "Passaremos um tempo juntos, trocaremos conselhos, e o príncipe se fará príncipe." (LESKOV, 2014, p. 157).

Ante a demora do ourives em concluir o serviço, o narrador se aborrece, pois o velho não parece dedicar à pedra a devida atenção. Paralelamente, o narrador alimenta ideias fixas envolvendo o artesão e a joia. Sonha estar nos campos de Merunice, onde sente o calor da terra, chegando a dizer: "[...] sob a inspiração de tudo isso, a granada comprada por mim começou de fato a me parecer animada por 'priscos fogos'." (LESKOV, 2014, p. 159).

Sob influência do piropo, o narrador rememora as superstições ligadas a diversas outras gemas, como o diamante, que afastaria sonhos maus, a safira, que fortaleceria o coração, a esmeralda, que curaria os olhos, e turquesa, que protegeria contra as quedas de cavalo. Frente a tal miríade de crenças, exclama: "Pois eis que me aparecia esse velho em desvairado delírio, e eu já estava pronto a delirar de novo com ele." (LESKOV, 2014, p. 159).

Wenzel, perante a impaciência do narrador, relata diferentes fábulas da tradição tcheca, que utiliza para explicar o nascimento do piropo. Notável é a referência aos milagres 
de São Nicolau, no qual uma mulher muito pobre enriquece ao encontrar um piropo. Temse nessa passagem uma referência à cultura popular e à religião ainda viva como uma forma de explicar os fenômenos.

Insatisfeito, o narrador solicita a devolução do piropo, ao que o ourives replica que retorne amanhã, quando a pedra estaria pronta. No dia seguinte, as exclamações do narrador são tais: “[...] o meu piropo estava realmente pronto. Nele, o 'limpa-chaminés' tinha desaparecido, e a pedra absorvia e expelia de si feixes de fogo denso, escuro. [...] A granada adquirira cor e cintilava: nela de fato ardia num fogo inextinguível uma gota encantada de sangue." (LESKOV, 2014, p. 164).

Imediatamente, o ourives repara a alexandrita no anel de seu cliente, e exclama:

Tchecos! Depressa! Vejam só, eis aqui aquela pedra russa profética da qual Ihes falei! Siberiana astuta! O tempo todo estava verde como a esperança, mas agora, com a aproximação do anoitecer, banhou-se de sangue. [...] Veja só que pedra! Nela a manhã é verde e a noite sangrenta... É o destino, é o destino do nobre tsar Aleksandr! (LESKOV, 2014, p. 164).

Wenzel se põe a chorar, e o próprio narrador se comove, reconhecendo em sua alexandrita uma dimensão que nunca percebera. $O$ conto se encerra com a passagem lapidar: "Eis o que às vezes significa olhar uma coisa com o espírito extraordinário da fantasia!" (LESKOV, 2014, p. 165).

\section{Considerações teóricas}

Noções teóricas relevantes para o estudo da literatura consideram comumente a abertura de uma obra a interpretações, tal como foi apontado por Benjamin (2014). Na ausência de explicações excessivas, é preservada ao leitor a possibilidade interpretativa na multiplicidade de sentidos. Em Alexandrita, o veredito sobre o estatuto fantástico das pedras cabe ao leitor, pois não há acordo entre as personagens. O próprio narrador oscila diante da crença do cabalista e cogita se o místico não teria razão em sua consideração anímica pelas gemas.

Tendo em vista a familiaridade de Leskov com as lendas e o folclore dos povos eslavos, a leitura permite retomar teorias não atreladas ao positivismo científico, ligadas, portanto, a concepções anímicas e religiosas. Nessa via, Benjamin (2014) aponta:

Leskov está à vontade tanto na distância espacial como na distância temporal [...] Nas lendas russas, Leskov encontrou aliados em seu combate à burocracia ortodoxa. Escreveu uma série de narrativas lendárias, cujo personagem central é o justo, raramente um asceta, em geral um homem simples e ativo, que se transforma em santo com a maior naturalidade. (BENJAMIN, 2014, p. 215-216).

Com mais força, justifica-se a escolha de um personagem vinculado à cabala e ao misticismo como o que apresenta ao narrador urbano uma cultura tradicional. O contraste de um personagem ligado a tradições populares e de outro envolto na artificialidade 
científica das sociedades burguesas remete à oposição literária entre campo e cidade. Tal antagonismo foi bem examinado por Raymond Williams (2011), que o descreve a partir do estabelecimento de Roma como capital de um império. Em reposta aos problemas citadinos, emerge em algumas obras a idealização do campo. Juvenal, como outros autores estudados por Williams, expressa em suas sátiras essa insatisfação com a vida urbana. 0 tema se atualiza em períodos literários, como no arcadismo de Tomás Antônio Gonzaga em Marília de Dirceu (1792), no realismo de Tolstói em Anna Kariênina (1875-1877), ou no de Eça de Queirós em A cidade e as serras (1901). No contexto de idealização campestre, é central a figura do pastor, ou homem simples, ligado à natureza e aos pensamentos mágicos e superstições. No conto, o cabalista é esse homem de que falava Benjamin (2014).

Outra consideração necessária diz respeito ao conceito literário do fantástico presente no conto. Referência central nesse quesito é Tzvetan Todorov (2012), que conceitua o fantástico como fruto de uma incompatibilidade entre as leis do mundo físico e os eventos presentes na narrativa. Da mesma forma, David Roas (2014) afirma:

[...] a narrativa fantástica se sustenta sobre a problematização dessa visão tradicional, arbitrária e compartilhada do real. A poética da ficção fantástica não apenas exige a coexistência do possível e do impossível dentro do mundo ficcional, como exige também (e acima de tudo) o questionamento de tal coexistência, tanto dentro como fora do texto. (ROAS, 2014, p. 93, grifos do autor).

No conto, o ponto de incompatibilidade está na oposição da crença anímica do ourives com a visão geológica do narrador. A narrativa faculta, por um lado, a leitura de uma das pedras como viva e da outra como profética do destino de um tsar, chegando mesmo a incorporarem caracteres dos povos russo e tcheco. Em contraste, uma leitura de cunho realista restringe-se à superstição ou à demência do cabalista e a um arrebatamento emotivo pelo narrador.

Seguindo os estudos dos textos tidos como fantásticos, maravilhosos ou insólitos, as passagens em que as pedras são dotadas de vida são compreendidas à luz do conceito do animismo. Como conceito, o animismo desponta na teoria antropológica de Edward Tylor (2016 [1871]) com intuito de explicar o fenômeno religioso. O animismo é definido da seguinte maneira: "[...] the deep-lying doctrine of Spiritual Beings, which embodies the very essence of Spiritualistic as opposed to Materialistic philosophy." (TYLOR, 2016, p. 425). ${ }^{1}$

Essa teoria foi retomada por Émile Durkheim (2013 [1912]), em sua obra Les Formes Élémentaires de la Vie Religieuse. Em seu entendimento, o animismo é a crença que,

[...] a pour objet les êtres spirituels, les esprits, âmes, génies, démons, divinités proprement dites, agents animés et conscientes comme l'homme, mais qui se distinguent pourtant de lui par la nature des pouvoirs qui leur sont attribués et, notamment, par ce caractère particulier qu'ils n'affectent

\footnotetext{
${ }^{1}[\ldots]$ a doutrina profunda dos seres espirituais, que incorpora a própria essência da filosofia espiritualista em oposição à filosofia materialista. (tradução nossa)
} 
pas les sens de la même façon : normalement, ils ne sont pas perceptibles à des humains. (DURKHEIM, 2013 [1912], p. 68). ${ }^{2}$

Durkheim reconhece essa proposição teórica - animismo como a crença em espíritos, agentes animados e conscientes não humanos - mas não a ratifica como fundamento do fenômeno religioso, ao contrário de Tylor (2016). Em seu lugar, propõe o totemismo, a crença no totem que ordena o clã. No sistema totêmico, os seres humanos entendem ter uma alma e um corpo iguais ao do totem.

Por sua vez, Sigmund Freud (2012 [1912-1913]), no capítulo "Animismo, magia e onipotência dos pensamentos", da obra Totem e tabu, também se vale das concepções anímicas, acrescentando:

O animismo é um sistema de pensamento, ele não só explica um fenômeno particular, mas permite compreender o mundo como unidade, a partir de um ponto. No curso dos tempos a humanidade produziu três grandes visões de mundo, se dermos crédito às autoridades: a animista (mitológica), a religiosa e a científica. Entre elas, a primeira criada, o animismo, é talvez a mais consequente e exaustiva, a que explica de maneira cabal a natureza do mundo. Essa primeira concepção de mundo da humanidade é uma teoria psicológica. Está além de nosso escopo demonstrar o quanto dela ainda se acha na vida moderna, seja em forma de superstição, ou bastante viva, como fundamento de nossa linguagem, crença e filosofia. (FREUD, 2012 [1912-1913], p. 124).

Observa-se existir uma concordância dos autores no que diz respeito ao conceito, ainda que cada um o aplique ao seu foco de estudo. Freud (2012 [1912-1913]) compara o animismo à psicopatologia e aos modos de pensar infantis. $O$ animismo é análogo a uma fase do desenvolvimento infantil, perceptível em desenhos e histórias produzidas por crianças, em que a objetos podem ser atribuídos rosto, emoções e movimento voluntário. Já no psiquismo neurótico, está presente no pensamento mágico, que fundamenta sintomas como rituais obsessivos e inibições conversivas.

Entre as passagens em que o animismo é identificável no conto destacam-se aquelas em que o ourives é apresentado ao cristal pelo narrador, afirmando já o conhecer e com ele ser capaz de conversar; em que conta como a joia resistiu à lapidação pelo suábio e se disfarçou de limpa-chaminés, embora fosse um rei ou um príncipe; em que a joia assume características do povo tcheco e quando exerce afinal fascínio sobre o narrador. Da mesma forma, à alexandrita é dada a capacidade de profetizar a morte do soberano russo.

Outra passagem de animismo marcante ocorre na recordação pelo narrador de uma história do século XVII, na qual outro tsar russo teria se valido de uma pedra bezoar para frustrar uma tentativa de envenenamento. Tal lembrança ocorre no momento em que o personagem começa a duvidar da ciência, em um prenúncio de sua aceitação do saber

\footnotetext{
2 [...] tem por objeto seres espirituais, espíritos, almas, gênios, demônios, divindades próprias, agentes animados e conscientes como o homem, mas que, no entanto, se distinguem dele pela natureza dos poderes atribuídos a eles e, notadamente, por este caráter particular de não afetarem os sentidos da mesma maneira: normalmente, eles não são perceptíveis aos humanos. (tradução nossa)
} 
tradicional do ourives.

Está certo que tudo isso aconteceu em priscas eras, quando tanto as pedras nas entranhas da terra quanto os planetas nas alturas celestes, todos eles se preocupavam com o destino do homem, e não atualmente, quando até nos céus há desgosto e sob a terra restou a indiferença fria pelo destino dos filhos dos homens e de lá não chegam vozes nem obediência. Todos os planetas, de novo descobertos, já não recebiam mais nenhuma atribuição nos horóscopos; há também muitas pedras novas, e todas são medidas, pesadas, comparadas em termos de peso específico e densidade, mas depois nada profetizam, não são úteis em nada. O seu tempo de falar ao homem já virou passado, agora são como "loquazes tribunos" que se transformaram em "peixes mudos". (LESKOV, 2014, p. 160-161).

A passagem acima ilustra a visão freudiana do animismo como teoria de explicação mítica. Nessa, tem-se uma visão de mundo em que a natureza é divina e os humanos não estão apartados da ordem cósmica. No animismo entendido como estágio precursor da religião, não há um sistema hierarquizado de crenças, de modo que humanos e não humanos constituem a mesma comunidade. É com institucionalização da religião, pelo advento de deuses, ordens monásticas e reinos do além, que se dá afinal a separação entre sagrado e profano. Nesse sistema hierárquico, é dado aos humanos um lugar distinto, acima dos seres naturais e abaixo dos divinos.

Um autor que atualmente se vale do conceito de animismo para explicar diferentes cosmovisões é o antropólogo Philippe Descola. Descola (2015) propõe uma ontologia quádrupla, que abriga desde o modo de pensar de diversos grupos indígenas até os pressupostos do conhecimento científico ocidental. Seu quadro ontológico considera a combinação de duas variáveis, a saber, a fisicalidade (elemento material componente dos corpos) e a interioridade (termo que abriga o conceito de alma) para estabelecer diferenças entre os sistemas de classificação de mundo.

O escopo das identificações baseadas na interação entre interioridade e fisicalidade é então bastante limitado: quando confrontado com uma alteridade até então desconhecida, humana ou não-humana, nosso sujeito hipotético pode concluir ou que este objeto possui elementos de fisicalidade e interioridade análogos aos seus, e isso eu chamo de totemismo; ou que a interioridade e fisicalidade deste objeto são inteiramente distintas da sua, e isso eu chamo de analogismo; ou que este objeto possui uma interioridade similar e uma fisicalidade diferente, e isso eu chamo de animismo; ou que este objeto é desprovido de interioridade, mas possui um tipo similar de fisicalidade, e isso eu chamo de naturalismo. Estas fórmulas definem quatro tipos de ontologias, isto é, sistemas de distribuição de propriedades entre objetos existentes no mundo, que em retorno fornecem pontos chave para formas sociocósmicas de associação e concepção de pessoas e nãopessoas. (DESCOLA, 2015, p. 12).

O quadro teórico de Descola (2015) permite interpretar o estatuto ontológico, ou seja, a natureza dos seres. No conto de Leskov (2014), é possível constatar o animismo, nos termos propostos pelo antropólogo, quando o cabalista personaliza as gemas que encontra. 
É possível pensar, então, que o personagem identifica a natureza das pedras com a dos humanos em geral, pois elas partilhariam com a humanidade essa característica da interioridade, ainda que sua fisicalidade difira completamente da humana.

$\mathrm{Na}$ cosmovisão anímica, a linguagem e os seres naturais têm uma relação íntima, concepção contrastante à moderna teorização, que enfatiza a arbitrariedade do signo linguístico com relação ao referente, ou seja, às coisas. O próprio nome das gemas indica uma relação de proximidade entre a natureza do objeto e sua agência, isto é, o fato de que as coisas podem atuar, não sendo apenas passíveis de manipulação humana. No caso da alexandrita, a explicação é narrada no próprio conto, uma vez que o mineral tem a função de espelhar a vida do soberano falecido tragicamente. Já o piropo (do grego múp e $\omega \Psi \psi$ ) significa o olho ou semblante de fogo, característica enfatizada no conto. Essa joia historicamente foi considerada de bom-gosto por nobres, vindo a ser adequada para presentear donzelas, emprestando, por isso, metonimicamente seu nome ao galanteio em terras espanholas. Granada, o outro nome da joia, é tomado da fruta romã, em latim pomum granatum, que com ela compartilha a cor vermelha vibrante. No século XVI, o explosivo portátil recebeu seu nome, via língua francesa, por semelhança física à mesma fruta. Esses exemplos indicam como o saber linguístico tradicional buscava uma aproximação entre os entes linguísticos e os não linguísticos.

\section{Considerações finais}

Alexandrita é um conto modelar na apresentação do animismo pois personaliza os dois minerais, atrelando-os à história dos países a que pertencem. Também é notória a relação de intimidade do ourives Wenzel com as joias, chegando a com elas conversar e a se valer do auxílio delas para a lapidação. Justamente essa personalização de seres inanimados é a característica central do animismo, uma concepção antropológica que tem valor literário na medida em que fundamenta a presença de vida nos objetos.

O animismo literário se enquadra no paradigma teórico do fantástico. Um texto é dito fantástico quando nele algo destoa do esperado na vida comum. Eis o caso do conto, pois as pedras falantes desafiam a compreensão científica vigente. Ainda assim, o conto, em sua pluralidade interpretativa, permite uma leitura realista, na qual os personagens são apenas supersticiosos ou beiram a loucura. Uma leitura que considere os aspectos mágicos permite, por outro lado, uma visão ampliada da realidade, pois considera outras fontes de saber, tais como o folclore e a tradição oral. Desse modo, a literatura tem se mantido ao longo da história como a arte que preserva saberes plurais, sem excluir a ciência, rejeitar a religião ou negar o misticismo.

Teorias do animismo permitem um diálogo entre disciplinas diversas e à primeira vista não relacionadas, tais como a antropologia, a filosofia, a teologia, a história, a biologia e a psicologia. Ilustrando estas considerações, Freud (2015 [1908]) escreve:

E não deixemos de retomar aquele tipo de obras em que não vimos criações originais, mas elaborações de material já existente e conhecido. Também 
nelas o escritor conserva alguma independência, que pode se manifestar na escolha do material e nas alterações que faz nele, frequentemente substanciais. Quando o material já é dado, porém, ele tem origem no tesouro popular dos mitos, lendas e fábulas. Não excluímos absolutamente a investigação desses produtos da psicologia dos povos, mas é bastante provável que os mitos, por exemplo, correspondam a vestígios deformados de fantasias-desejos de nações inteiras, a sonhos seculares da jovem humanidade. (FREUD, 2015 [1908], p. 337).

Convém lembrar que a própria construção teórica da psicanálise se valeu de um conjunto de conhecimentos reunidos pela literatura. A obra literária inspira e fomenta o desenvolvimento de outras áreas, bem como delas se vale para compor suas narrativas.

A investigação de obras literárias sob o prisma anímico é hoje empreendida a partir da constelação conceitual do insólito (SILVA; SILVEIRA, 2016). Os conceitos de insólito, fantástico, maravilhoso, realismo mágico e materialismo animista africano têm sido estudados, por exemplo, pelo Grupo de Trabalho Vertentes do Insólito Ficcional, da Universidade Estadual do Rio de Janeiro. Já o recurso à teoria antropológica se justifica toda vez que é necessário um conjunto explicativo para compreender os diversos modos de relação dos seres humanos e não humanos. A literatura de matiz insólito, fantástico e maravilhoso é pródiga em oferecer entes que desafiam os limites da compreensão biológica contemporânea. É comum a presença de seres tidos pela ciência como desprovidos de intelecto e agência. Ante as dificuldades do pensamento científico em compreendê-los, é na cosmovisão de inspiração indígena estudada pela antropologia que se encontram os elementos explicativos necessários. As criações dos povos tradicionais, afinal, são análogas às personificações imprescindíveis através das quais o autor de ficção expressa, na forma de seres animados, seus conflitos e aspirações.

\section{Referências}

BENJAMIN, Walter. O Narrador. Considerações sobre a obra de Nikolai Leskov. In: BENJAMIN, Walter. Magia e técnica, arte e política: ensaios sobre literatura e história da cultura. Trad. de Sérgio Paulo Rouanet. São Paulo: Brasiliense, 2014, p. 213-240.

DESCOLA, Philippe. Além de natureza e cultura. Tessituras, Pelotas, v. 3, n. 1, p. 7-33, jan./jun. 2015.

DURKHEIM, Émile. Les formes élémentaires de la vie religieuse. Paris: Presse Universitaire de France, 2013.

FREUD, Sigmund. Obras completas: O delírio e os sonhos na Gradiva, Análise da fobia de um garoto de cinco anos e outros textos (1906 - 1909). Trad. de Paulo César de Souza. São Paulo: Companhia das Letras, 2015. v. 8.

FREUD, Sigmund. Obras completas: totem e tabu, contribuição à história do movimento psicanalítico e outros textos (1912 - 1914). Trad. de Paulo César de Souza. São Paulo: Companhia das Letras, 2012. v. 11. 
LESKOV, Nikolai. A fraude e outras histórias. Trad. de Denise Sales. São Paulo: Editora 34, 2014.

ROAS, David A ameaça do fantástico: aproximações teóricas. Trad. de Julián Fuks. São Paulo: Editora Unesp, 2014.

SILVA, Tânia Regina Silva da; SILVEIRA, Regina da Costa da. A insólita criança divina em A menina de lá, de Guimarães Rosa. Nonada: Letras em Revista, v. 2, n. 27, p. 107-119. set. 2016.

TODOROV, Tzvetan. Introdução à literatura fantástica. Trad. de Maria Clara Correa Castello. São Paulo: Perspectiva, 2012.

TYLOR, Edward Burnett. Primitive culture. Mineola: Dover Publications Inc, 2016. v. 1.

VÁSSINA, Elena. Nikolai Leskov, o mais original dos escritores russos. In: LESKOV, Nikolai. A fraude e outras histórias. Trad. de Denise Sales. São Paulo: Editora 34, 2014, p. 203-217.

WILLIAMS, Raymond. O campo e a cidade: na história e na literatura. Trad. de Paulo Henriques Britto. São Paulo: Companhia das Letras, 2011.

\section{NOTAS DE AUTORIA}

Marcos Lampert Varnieri (marcoslvarnieri@gmail.com) é doutorando em Letras pela Universidade Federal do Rio Grande do Sul (UFRGS) em Estudos de Literatura, na linha de pesquisa Pós-colonialismo e Identidades. A pesquisa de doutorado trata dos cantos do povo Tikmũ'ũn-Maxakali lidos nas perspectivas do xamanismo e do animismo. Mestre em Letras pela UniRitter Laureate International Universities. Desenvolveu sua dissertação sobre a obra épica finlandesa Kalevala. Graduado em Licenciatura em Língua Inglesa e Literaturas de Língua Inglesa pela mesma instituição.

\section{Agradecimentos}

Não se aplica.

\section{Como citar esse artigo de acordo com as normas da ABNT}

VARNIERI, Marcos Lampert. Nikolai Leskov e o animismo: falar com pedras no conto Alexandrita. Anuário de Literatura, Florianópolis, v. 26, p. 01-12, 2021.

\section{Contribuição de autoria}

Não se aplica.

\section{Financiamento}

Não se aplica.

Consentimento de uso de imagem

Não se aplica.

Aprovação de comitê de ética em pesquisa

Não se aplica.

\section{Conflito de interesses}

Não se aplica.

\section{Licença de uso}

Os/as autores/as cedem à Revista Anuário de Literatura os direitos exclusivos de primeira publicação, com o trabalho simultaneamente licenciado sob a Licença Creative Commons Attribution (CC BY) 4.0 International. Esta licença permite que terceiros remixem, adaptem e criem a partir do trabalho publicado, atribuindo 0 devido crédito de autoria e publicação inicial neste periódico. Os autores têm autorização para assumir 
contratos adicionais separadamente, para distribuição não exclusiva da versão do trabalho publicada neste periódico (ex.: publicar em repositório institucional, em site pessoal, publicar uma tradução, ou como capítulo de livro), com reconhecimento de autoria e publicação inicial neste periódico.

\section{Publisher}

Universidade Federal de Santa Catarina. Programa de Pós-graduação em Literatura. Publicação no Portal de Periódicos UFSC. As ideias expressadas neste artigo são de responsabilidade de seus/suas autores/as, não representando, necessariamente, a opinião dos/as editores/as ou da universidade.

\section{Histórico}

Recebido em: 02/07/2021

Aprovado em: 07/10/2021

Publicado em: 14/12/2021 